\title{
Improving Products' Ergonomic Value Using Intelligent Decision Support System
}

\author{
Jasmin Kaljun* - Bojan Dolšak \\ University of Maribor, Faculty of Mechanical Engineering, Slovenia
}

During the process of defining suitable design solutions, a designer has to consider a wide range of influential factors. Ergonomics certainly belongs to more complex ones. Less experienced designers could encounter several problems during this design stage. Although some literature can be found about ergonomic design of hand tools, a designer still has to have amassed quite a lot of experience and knowledge in the field of ergonomic, in order to choose and carry out appropriate design and redesign actions. Existing computer tools for ergonomic design are not able to assist a designer with higher level advice within design process. An intelligent decision support system has been developed in order to overcome this bottleneck. This paper presents a knowledge base, containing ergonomic design knowledge specific for hand tools design. A pneumatic hammer handle design is used as a case study to show how ergonomic design knowledge built in the system is used to improve the ergonomic value of the product.

Keywords: ergonomics, intelligent support, hand tools, knowledge acquisition, handle design, pneumatic hammer

\section{O INTRODUCTION}

During the design of the product for everyday use, various influential factors have to be considered. Ergonomic value of the product is certainly one of the issues that need to be addressed. A less experienced designer could meet several problems to find ergonomically appropriate design solution. Although the existing ergonomic Computer Aided Design (CAD) software that is discussed in Section 1 can provide some assistance in ergonomic design evaluation, the designer still has to possess a substantial experience and knowledge in the field of ergonomics in order to choose and carry out adequate design actions to improve the ergonomic value of the product in reasonable time.

Product ergonomics is an interdisciplinary scientific discipline concerned with understanding interactions among humans and other elements of a system. In this context, the user has a central role in product development process [1]. Product ergonomics applies theory, principles, data and methods to optimize human well-being and overall system performance.

The ergonomic quality of a product can be defined by a match between anthropometric data and formal attributes. However, the quality of ergonomics is not only based on anthropometrics, as the field of human factors has been realizing over the past thirty years [2]. Cognitive and experiential processes play a major role in deciding whether a design is usable, efficient, satisfying, easy to use, or comfortable.

On the other hand, ergonomic solution must not adversely affect other characteristics of the product. Among others, ergonomics is very much connected to the aesthetic appearance of the product and seeking an optimal balance is a delicate manner [3]. It is exactly this kind of skill that a good designer needs to have: finding the optimal balance between the two aspects.

In order to support a decision making process when performing this task, a prototype of the intelligent advisory system, which is briefly presented in Section 2, is being developed. In continuation of this paper we will concentrate on ergonomic part of the system.

Ergonomic design knowledge is discussed in Section 3 by presenting important ergonomic design goals and corresponding design recommendations. We have limited our research to certain group of products - hand tools, as representatives of ergonomically significant products that are manipulated with upper extremities like many household appliances, etc.

A case study of knowledge base application is presented in Section 4 and concluding remarks are given in the last section.

\section{EXISTING ERGONOMIC CAD TOOLS}

In the field of ergonomic CAD, the development process has focused on integrated tools based on threedimensional modelling of the product and the human body that enable the use of ergonomic data originating from various sources, when performing ergonomic analysis of the product. This enables a designer to use a single analysis/simulation tool to evaluate and assess clearances, reach, visual requirements, and postural comfort at the earliest stages of design [4]. Moreover, it makes possible for a designer to incorporate important features into designs, thus minimizing the risk of discomfort or even injuries way before a person ever physically encounters the product or working place that is subject of development. 
Using an interactive interface, designers are able to manipulate both, the human form and the product design [5].

Two different approaches to developing such software tools have been taken [6]. One approach is oriented towards the development of the so called stand-alone ergonomic CAD software with ergonomic assessment capabilities and a built-in tree-dimensional CAD module. The alternative approach leads to the development of compatible ergonomic software based on special modules that enable ergonomic analysis within commercially available CAD systems, which are used to provide three-dimensional modelling and user interface.

Some of the best-known representatives of both groups of ergonomic CAD software are presented in Table 1.

In continuation of this section more detail description emphasizing some application characteristics is given for each group in a separate sub-section.

Table 1. Representatives of ergonomic CAD tools

\begin{tabular}{cc}
\hline $\begin{array}{c}\text { Stand-alone } \\
\text { ergonomic CAD tools }\end{array}$ & $\begin{array}{c}\text { Compatible } \\
\text { ergonomic CAD tools }\end{array}$ \\
\hline SAMMIE & SAFEWORK \\
\hline APOLIN & MINTAC \\
\hline TADAPS & ErgOSHAPE \\
\hline Deneb/ERGO & HUMAN \\
\hline ERGOMAN & RAMSIS \\
\hline ErgOSPACE & ANYBODY \\
\hline
\end{tabular}

\subsection{Stand-alone Ergonomic CAD Software}

Stand-alone ergonomic software is applied independently of the other CAD software used in product development processes. Thus, the user should learn terminology, command structures, and modelling techniques that are usually different from those in commercial CAD systems. Fortunately, many of these systems have the ability to import geometric models as modelled in other CAD tools, where the complexities of the models can be taken in consideration.

The working environment is composed of the product model and the model of a human that is assigned to perform virtual application of the product [7]. After the modelling/import is finished, the parameters for various ergonomic analyses are set, and the analyses are carried out. The evaluation of the analyses results is the next step in the design process, where ergonomic satisfaction of the product needs to be evaluated. If re-modelling of the product is needed, the whole cycle is repeated until the resulting model of the product does not satisfy ergonomic criteria. Even then, certain changes may still be necessary in order to improve other design requirements, as for example, aesthetics and manufacturability.

\subsection{Compatible Ergonomic CAD Software}

Compatible ergonomic software has been designed for access within available commercial CAD systems, as for example [8] and [9]. These tools take the advantage of the designers' familiarity with the terminology, techniques, and command structures of commonly used CAD programs. The main advantage of these tools is the application of a single geometric model for all phases of the design process, which prevents many problems related to data transfer.

Similarly to the application of stand-alone ergonomic CAD software, the development process starts with a concept design and usually an ergonomically-imperfect design candidate, which represent the starting point for compatible ergonomic $\mathrm{CAD}$ tool. The exact three-dimensional virtual model of the product is modelled using a geometric modeller of the commercial CAD software. When the model is finished, the ergonomic tool is run within the commercial CAD system, where the working environment and a human model are prepared. The modelling is followed by assigning proper values to the ergonomic analyses parameters. In the next step, ergonomic analyses are carried out. Immediately after the results of the ergonomic analyses are evaluated, the product can be re-designed and re-modelled in order to correct eventual ergonomic imperfection.

Alternatively, the process can be continued towards other analyses that need to be carried out for the model. The result of such multi-criteria analysis [10], conducted within single software environment is a final design solution of the product that fulfils all ergonomic, mechanical, and other demands and conditions.

\section{INTELLIGENT SUPPORT TO ERGONOMIC DESIGN PROCESS}

Various advanced approaches have been investigated to improve the product development process, such as those reported in [11] and [12]. The need for integration of ergonomics into product design is evident for quite a long time now [13]. However, the need for knowledge-based decision support within ergonomic design process has been defined more recently. It is based on the cognition that conventional ergonomic $\mathrm{CAD}$ tools do not meet the expectations 
of design engineers. While they offer a reasonable level of support in various ergonomic analyses [14], they fail to provide any kind of meaningful advice from an engineering point of view in terms of design recommendations leading to better ergonomic value of the product, when appropriate.

In order to overcome this bottleneck and to round off a cognitive cycle [15] for continuous improvement of product's ergonomics, we are developing a prototype of an intelligent advisory system Oscar, based on expert design knowledge management.

A possible logical frame of ergonomic knowledge management has been proposed by $\mathrm{Du}$ et al. at Computer-Aided Industrial Design \& Conceptual Design conference in 2009 [16]. In the proposed frame the aesthetic appearance of the product is not considered as an influential parameter, which, however, is the case in our system, as presented in Fig. 1. Oscar is namely composed of two sub-systems that can be applied in two different modes. They can be used independently from each other, or simultaneously and interdependent on the same design project.

In the simultaneous mode, the task of the inference engine is not only to derive and propose recommendations for both, ergonomic and aesthetic design improvements, but also to synchronize and harmonize possible design solutions in order to find the optimal balance between the two aspects of the product being developed.

The intelligent decision support system Oscar is still a research prototype, and as such, a subject of intensive development, especially the more subjective part of the system dealing with engineering aesthetics and aesthetic ergonomics [17]. On the other hand, the ergonomic part of the system, which is based on more objective ergonomic design knowledge built in the knowledge base of the system, is functional and thus, discussed below in more detail.

Basically, the intelligent advisory system is a computer system that emulates the decision- making ability of a human expert. Such systems are designed to solve complex problems by reasoning about knowledge, like a human expert, and not by following the procedure of a developer as is the case in conventional programming [18].

The structure of the intelligent advisory system is unique, and significantly different from traditional programs. In foundation, the system is divided into three parts. The first part is fixed, independent of the rest of the system, called the inference engine. The second part is variable, called the knowledge base. The third part, which serves as a communication module is called user interface. When running intelligent advisory system, the inference engine reasons about the knowledge base like a human expert and communicates with user through user interface.

In the intelligent advisory system technology, the knowledge base is expressed with natural language IF-THEN styled rules, called production rules [18].

Usually inference engine runs in the so called conversational mode. This simply means that the inference engine requests initial data from the user at the start. Since problems are usually complex, the system often cannot find a suitable solution using only initial data. Therefore, the system has to find the way to solve the problem by requesting the missing data form the user.

With additional data the system gradually approaches to the solution.

The user feels like a participant in a dialogue led by an expert. To control a dialogue, the inference engine three different techniques: forward chaining, backward chaining and mixed chaining [19]. Forward chaining is a technique where the inference engine searches the solution (goal) by using specified procedure and asking questions. In backward chaining, the inference engine knows the solution and attempts to find production rules to support the solution. In mixed chaining the inference engine has an "idea" of the solution but cannot simply confirm it. Therefore,

\section{INTELLIGENT SYSTEM OSCAR}
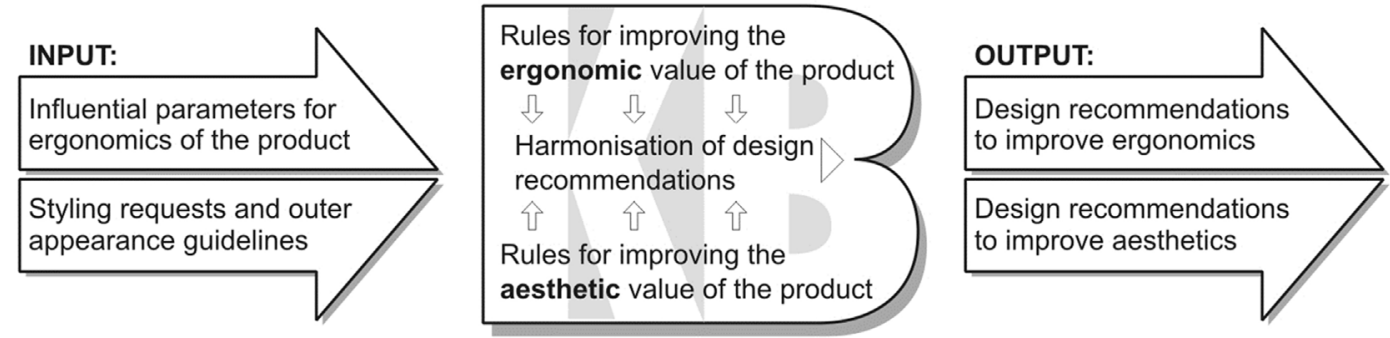

Fig. 1. Basic structure of the intelligent advisory system Oscar 
the inference engine deduces in forward chaining the technique using information from previous user responses before asking the next question. So, quite often the inference engine deduces the answer to the next question before asking it.

When developing Oscar, a development environment named Exsys Corvid [20] has been used. The Corvid enables developer to build the knowledge base using natural language. User interface is built simultaneously with knowledge base. The Corvid provides developer with configurable inference engine. The prototype is built as java applet to be used online.

\section{ERGONOMIC DESIGN KNOWLEDGE}

The main focus of ergonomic design is compatibility of objects and environments with human factors. It seeks to harmonize functionality of the tasks with capabilities of humans performing them. Ergonomic design knowledge is extensive.

It considers not only anthropometrics and biomechanics, but also cognitive issues. For this reason, we decided to limit our research on ergonomic design of hand tools [21].

Similarly to some other products that are manipulated with upper extremities, static and dynamic anthropometry, biomechanics and anatomy of the human hand (Fig. 2) needs to be taken into consideration [22].

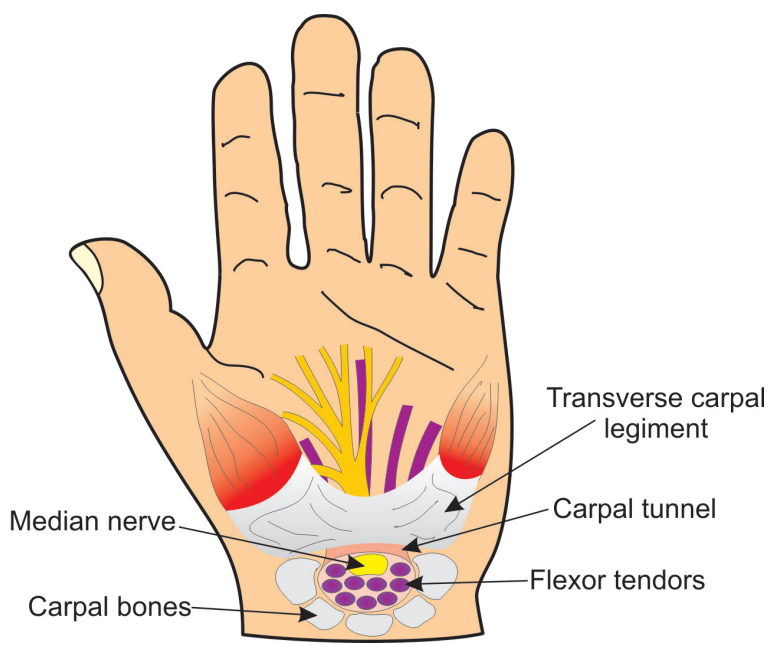

Fig. 2. Human hand

The development of a knowledge base related to ergonomic design of hand tools has been carried out in three steps. First of all, all crucial ergonomic design goals were defined by studying literature and interviewing some experts. In the next step, these goals have been associated with respective design recommendations that ensure a certain goal to be accomplished. Knowledge acquisition was again a combination of literature survey and transfer of human knowledge and experience. In the last step, the collected knowledge was organized and written in the form of production rules to be used by the intelligent system.

Different classes are interconnected with various attributes and their values in head of the rule in order to describe case specific situation, in which recommendations for product design that are listed in the body of the rule should be taken into consideration, as for example:

IF

Type is Hand tools for specific tasks

Contact Element is Grip

Trigger Style is Palm push button

THEN

Ergonomic goal:

Reduce tissue compression

Design Recommendations:

Design contoured handle

Use triggers of adequate length (thickness)

Design oval/elliptical cross-section of the handle

Avoid sharp edges

In the following sub-sections, the most important ergonomic design goals and respective design recommendations related to hand tools are presented. The rule shown here is an example of how this knowledge is encoded in the system and refers to the case study discussed in the next section of this paper.

\subsection{Dimensions and Configurations}

In order to define appropriate dimensions and configurations to be respected in hand tools design, the anthropometrical data related to human hand are transformed into design recommendations (Table 2).

Table 2. Anthropometrical recommendations

\begin{tabular}{ll}
\hline Attribute & Value \\
\hline handle cross - section & round or oval \\
\hline handle diameter - power grip & $\min . \varnothing 25$ to $45 \mathrm{~mm}$ \\
\hline handle diameter - precision grip & $\min . \varnothing 7$ to $15 \mathrm{~mm}$ \\
\hline handle length (palm side) & $\min .100 \mathrm{~mm}$ \\
\hline handle length (palm side) - gloves & $\min .114 \mathrm{~mm}$ \\
\hline handle length (finger side) & $\min .78 \mathrm{~mm}$ \\
\hline handle length (finger side) - gloves & $\min .90 \mathrm{~mm}$ \\
\hline pistol grip handle angle & $7^{\circ}$ to $10^{\circ}$ \\
\hline finger clearness & $\min .35 \mathrm{~mm}$ \\
\hline
\end{tabular}


Fig. 3 shows in a graphic form the recommended dimensions for a handle that will be used in the next section as a case study.

It can be seen that the length of the handle allows the use of protective leather gloves, as shown in the next section (Fig. 9).

It is important to select correct handle diameter to provide optimal grip span and consequently optimal grip force. Cylindrically shaped handles are usually not applied to the tool where rotation of the hand around the grip is not expected. In such cases handles have oval or rectangular cross - section with a grip span between 35 to $50 \mathrm{~mm}$, considering the use of protective leather gloves.

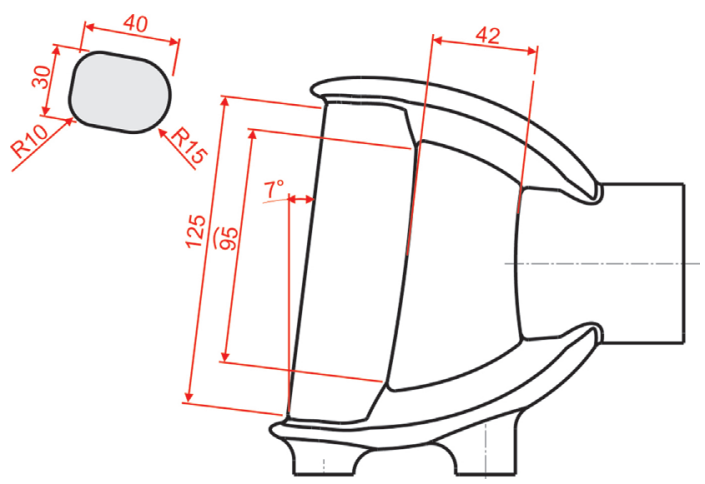

Fig. 3. Recommended handle dimensions

\subsection{Maintain Neutral Straight Wrist Position}

All movements of the wrist, especially those cases in extremes of these movements, in connection with repetitive finger actions or prolonged forceful finger exertions, place extensive pressures upon the flexor tendons passing through the carpal tunnel. This may cause inflammation of tendon sheath and pressure upon the median nerve and in consequence even serious injuries. Bending the wrist, while performing the task, which requires repeated rotation or twisting of the forearm, can also stretch and pull the tendon connection at the elbow. Repeated stress at this connection can cause irritation and swelling, leading to the so called tennis elbow. When the wrist is straight, tendons can slide easily through the sheath. It is thus very important to maintain the wrist in neutral straight position.

Design recommendations:

- Use pistol grip for tools, which are used on vertical surfaces. The type of the grip used depends on the work piece height.

- Use inline cylindrical grip for tools, which are used on horizontal surfaces. Again, the type depends on the work piece height. For example, for the horizontal work piece in a femur level, the pistol grip is suitable.

- Use deviated handles, which maintain the straight wrist for tools for specific tasks (Fig. 4).

- Provide adjustable handles for tools that will be used in several different positions.

- Use power tools instead of traditional tools for tasks that require highly repetitive manual motions.

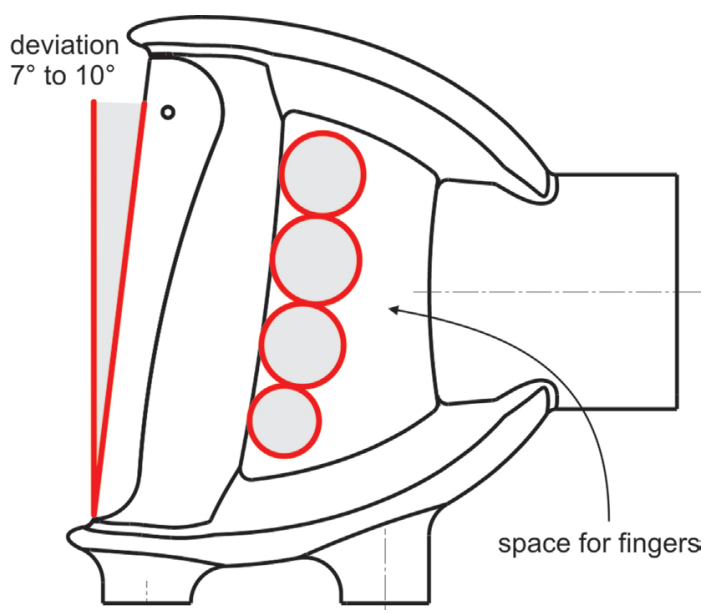

Fig. 4. Design to assure neutral wrist position (when protective gloves are applied, diameter of circles is bigger)

\subsection{Avoid Tissue Compression}

Local pressure upon tissues of a palm or fingers may cause loss of circulation, damage of nerves, leading to tingling of fingers; or damage of tendons or muscles, leading to pain and difficult hand movement. This unsuitable pressure is caused by insufficient handle length (thickness) or hard surfaces on handles.

Recommendations:

- Use handles of adequate length (thickness) that span the entire hand.

- Use padding to soften the handle surface.

- Use contoured handles which spread the pressure over a large area (Fig. 5).

Among the various tool handle design characteristics, handle diameter has been studied extensively because it is an important factor to maximize grip strength, minimize stress on the digit flexor tendons, first metacarpal ulnar collateral and carpometacarpal ligaments, and it can also influence force exertion in manual work.

Different independent studies have been carried out to determine optimal handle diameter with maximal grip force [23]. On the basis of this research 
work, an optimal handle diameter to develop the maximal hand grip force is between 25 and $45 \mathrm{~mm}$ and is larger for men. In case of cylindrical grip, circumference is therefore between 78 and $141 \mathrm{~mm}$. Circumference of the presented grip is $140 \mathrm{~mm}$, which is close to upper optimal limit, however due to the prevention of tissue compression on the trigger, the grip has to be wider.

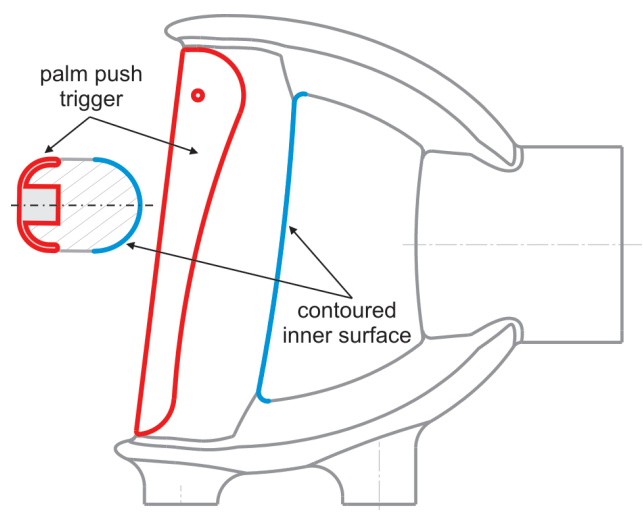

Fig. 5. Design to prevent tissue compression

According to [23], average grip force for male when using optimal grip diameter is between 300 and $660 \mathrm{~N}$.

\subsection{Reduce the Excessive Forces}

Exertion of high finger forces, either prolonged or repetitive, can stretch and in turn fray tendons. This kind of damage can make it difficult for the tendon to slide through the tendon sheath, which can lead to further irritation and swelling. Irritation and swelling can lead to restriction of the tendon movement through the sheath, eventually causing the so called trigger finger. Especially a combination of both repetitive and prolonged motions may lead to permanent disorders, and carpal tunnel syndrome.

Excessive forces may also overload muscles and create fatigue and potential for injuries. Highly repetitive tasks which may not use such a great force can also cause irritation. Contact with sharp edges of tools or bending the wrist greatly increases the hazard associated with the use of forceful finger exertions.

Recommendations:

- Use power grips (Fig. 6) instead of forceful pinch grips with straight fingers. One can exert more force with the power grip than pinch grip.

- Use the appropriate grip size. To generate the most grasping force, design objects to a size that permits the thumb and forefinger to overlap slightly.
- Reduce resistance of tool activators (triggers, trigger lockers etc.).

- Use the alternative non-mechanical triggers (vacuum, optical etc.).

- Increase leverage within the tool. Add more fulcrums. Extend lever arm.

- Improve tool balance. Reduce tool length. Locate heavy masses such as motor, battery, etc. as close as possible to the wrist.

- Where a relatively large force is needed to activate the tool (hydraulic or pneumatic power tools), use trigger levers for more fingers instead of a single point trigger to spread the activating.

- Avoid sharp edges on triggers and handles.

- Add the second handle located near the front end of the tool to spread exertion between two hands. In this way the control of heavy tools and tools operating with large torque is also improved.

- Increase contact friction on handles by using slip resistant, nonporous and slightly compressible materials.

- Use a collar where the force is applied coaxially to the handle. It may reduce the grasping force.

- Use the expanding springs to prevent the constant need of opening handles.

- Use the power tools instead of traditional tools for tasks which require high excessive motion.

\subsection{Ensure Proper Height for the Task}

Working in a position that implies the elbow raised and maintained above the shoulder height for prolonged periods can trap nerves and blood vessels under the bone and muscle, which leads to numbness and tingling in the hands, and can fatigue the muscles of the shoulder and upper arm. It is therefore, required to design the tool in a way that ensures proper height of the task.

Recommendations:

- Design tool handles and other features to fit in the proper working height level.

- Reduce muscle exertion and improve control over the tool.

- For heavier manual work with the heavy power tools, design the tools for use at the hip level, with the tool close to the body and the angle between the upper arm and forearm in range of 90 to $120^{\circ}$.

- For precision work with lighter tools, design the tools for the use at the elbow level and higher.

- Use extended poles for work above the head. 


\subsection{Protect Against Vibrations, Heat, Noise}

Local vibrations may cause circulation disorders, white fingers or other serious cumulative trauma disorders. Enhanced noise may increase fatigue and stress; and may cause problems of hearing. The hand may be affected by vibrations in range of 1.5 to $80 \mathrm{~g}$ and 8 to $500 \mathrm{~Hz}$.

Recommendations:

- Improve the overall tool design taking into account the natural frequencies to decrease vibration distribution from the motor or other source of vibrations into other connected parts and handles.

- Use isolation mounts such as springs and rubber silent blocks between individual parts.

- Use damped tool handles.

- Use damping materials on a handle surface.

- Use heated handles where needed.

- Cover hot parts of the tool such as motors.

- Clean and adjust power tools periodically.

Remark: sound (noise) is a consequence of vibrations, actually vibrations transferred from the tool into an air and then into human ears; therefore the same recommendations can be used analogously for decreasing the level of noise.

\subsection{Reduce Static Load}

Holding the same position for a period of time can cause pain and fatigue. The primary problem is duration. However, negative influence is additionally increased by high force or awkward posture.

Recommendations:

- Reduce the weight of the tool.

- Use tool supports.

- Improve tool balance. Reduce tool length. Locate heavy masses such as motor, battery, etc. as close as possible to the wrist.

\subsection{Cognitive Ergonomics}

Cognitive ergonomics deals with a mental interrelationship between the human and the product. The goal to be achieved by using design recommendations is to prevent mental overload and misunderstanding when using certain product - in our case the hand tool.

Recommendations:

- Use red colour for switch buttons or for warnings and dangers.

- Use vertical switches with the following meaning: up-ON, down-OFF.
- Turning a dial to the right increases the speed, torque or power.

- Use numbers: 1 (slow), ..., 10 (fast).

- Use the right hand to operate the trigger and other controls.

\section{CASE STUDY}

In order to demonstrate practical application of the ergonomic design knowledge built in the intelligent decision support system Oscar, a case study dealing with redesign of the pneumatic hammer handle has been carried out.

The goal of the project was a redesign of the handle and new design of the casing for the pneumatic hammer presented in Fig. 6. A basic edition of the existing pneumatic hammer was not equipped with body casing; simple rubber tubes were provided instead of body casing on customer request.

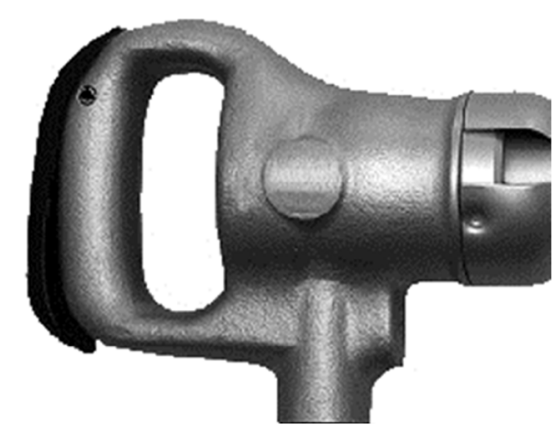

Fig. 6. Existing pneumatic hammer (handle)

Pneumatic hammers are hand tools used for smashing and drilling hard materials. They are mostly used in the field of civil engineering and mining industry. Pneumatic hammers belong to a group of tools powered with compressed air and subgroup shock tools.

A pneumatic hammer is a very useful tool for many purposes. Physical properties of air allow it to accumulate relatively big amounts of energy, which is very important for the shock power of a pneumatic hammer. Shock power is one of more important features of a pneumatic hammer, as it is relatively high regarding to the weight of the tool itself.

The hammer that was chosen for the case study was underdeveloped from both, ergonomic and aesthetic point of view. The manufacturing company was aware of that, and took the opportunity using our innovative technologies to improve the design of their product in order to increase their competitiveness [24] and [25]. 
It could be argued that aesthetics is not important for such a tool. Yet, it has an important influence on the user's cognitive comfort and emotional contentment. However, our primary goal for the case study, presented in this paper, was the improvement of the ergonomic value of the tool with emphasize on the handle design.

Quality and usefulness of advice provided by the intelligent system depends on the quality of input parameters. This is why a lot of attention should to be dedicated to define them. Table 3 presents the most important influential parameters and their values as they were presented to the system.

Table 3. Most important input parameters

\begin{tabular}{ll}
\hline Parameter & Value \\
\hline user information & male, 18 to 55 years old, average \\
\hline place of use & constructing places, dust \\
\hline application direction & mainly horizontal \\
\hline application technique & one or both handed, 1 operator \\
\hline protective equipment & protective leather gloves \\
\hline mech. characteristic & solidness, stability, low weight \\
\hline critical areas & rear handle, front hand support \\
\hline emotional contentment & solidness, reliability, power \\
\hline
\end{tabular}

In the next step, the knowledge base built in the system was applied to generate ergonomic design recommendations.

In the case study presented here, redesign recommendations proposed by the intelligent system Oscar can be summarized in three groups:

- change the shape and dimensions of the handle,

- change the cross-section of the handle,

- change the position of the handle.

Considering all the recommendations based on the ergonomic knowledge built in the system and presented in previous section of this paper, including Figs. 4 to 6 , a virtual model of the new pneumatic hammer handle was modelled (Fig. 7).

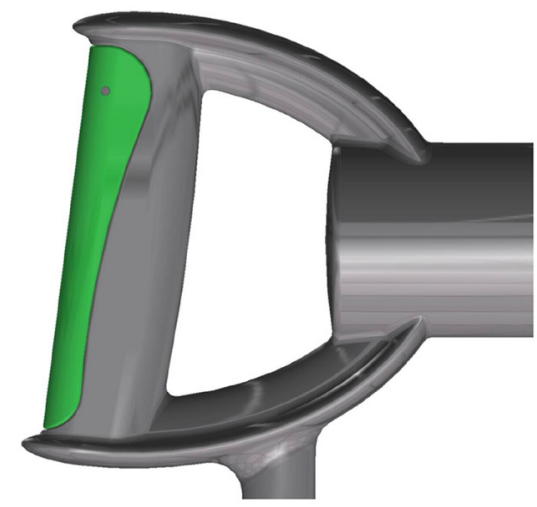

Fig. 7. Virtual model of redesigned handle
The first step of the evaluation has been made using a virtual hand of average (50 th percentile) male. In that way the size of the grip and finger space has been tested. Visual inspection of the virtual hand/ handle assembly (Fig. 8) has confirmed dimensional suitability.

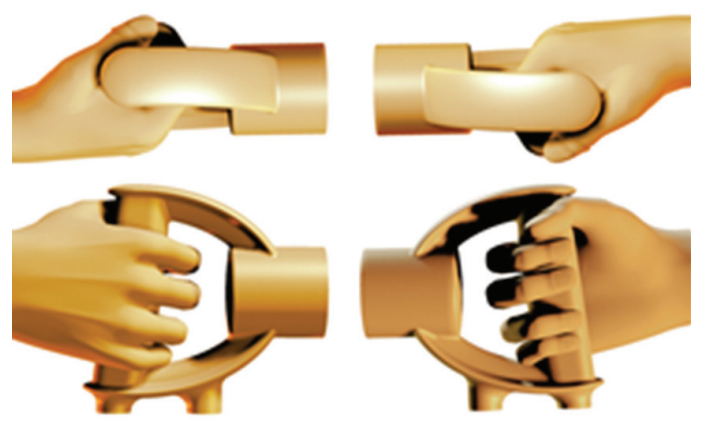

Fig. 8. Virtual evaluation

The next step was actual evaluation of physical model. On the basis of the computer model of the handle, a prototype of the handle has been build using rapid prototyping technique $3 \mathrm{D}$ object printing. The prototype of the handle made in this way has been used for practical ergonomic evaluation by the users of the existing pneumatic hammers (Fig. 9). Two connectors for the tube with compressed air were designed in order to find a better position in terms of tool balance when the tube is attached to it.

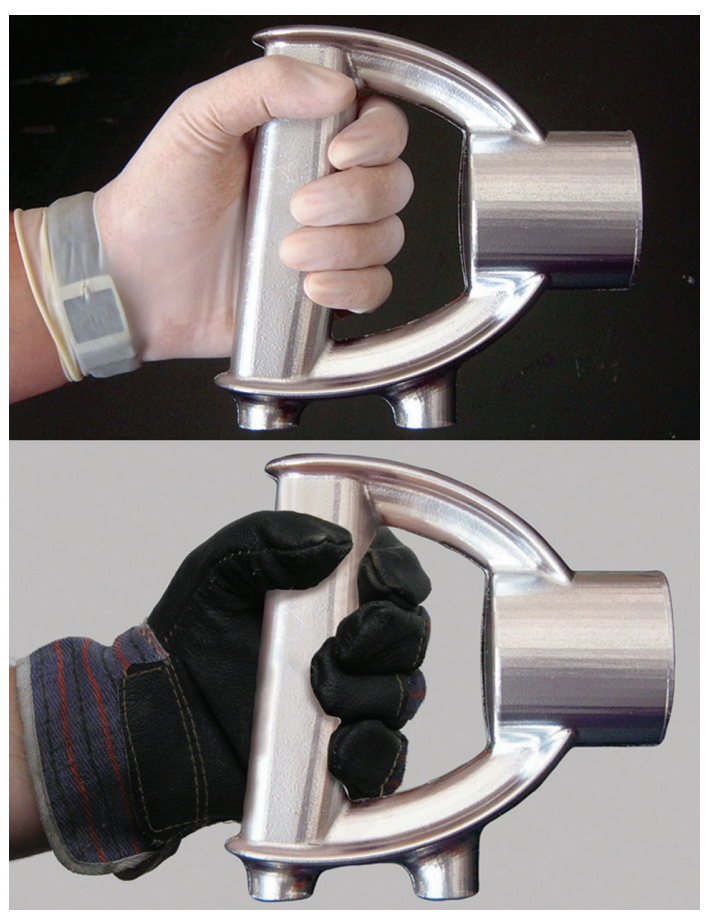

Fig. 9. Evaluation using rapid prototyping 
Workers (15 persons from different constructing companies) who are using this tool daily, were asked to assess both handle designs (existing and new) using grades from 1 to 5 in areas:

- overall feeling of holding the grip in the hand,

- grip strength and stability,

- finger space needed for manipulation,

- pain or tension in the hand (grade 5 - no pain or tension).

Fig. 10 shows the results of assessment. The results of the evaluation show that the overall ergonomic value of the handle has been significantly improved by providing more space for fingers (also for a hand wearing a protective gloves), better wrist position, and better grip of the handle.

However, due to the prototype limitations, the evaluation of handle has not been performed during the work process itself (use of pneumatic hammer in practice). Future research work will also be oriented towards simulation techniques that will enable virtual evaluation of hand tool - user interaction, using principles of simulating nonlinear materials (i.e. human tissue) using cross-linked simulations [26] and [27].

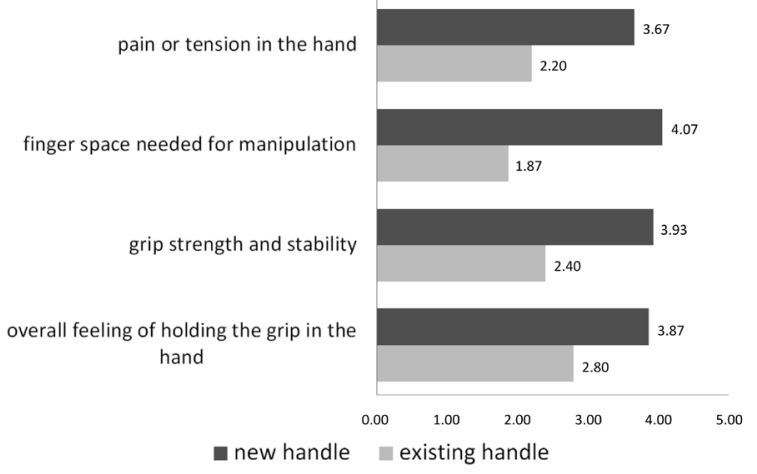

Fig. 10. Assessment results

\section{CONCLUSIONS}

Among other design factors, ergonomics play an important and complex part in the product design process. Regarding the complexity, multi-factors coupling and fuzziness of ergonomic knowledge, an intelligent support to ergonomic design in the form of advisory decision support system is proposed.

In this context, the knowledge related to ergonomic design of hand tools has been collected, organised and encoded in the form of production rules, which were found to be the most appropriate formalism due to their transparency and closeness with the human way of decision making process.
The knowledge built in the prototype of the intelligent system named Oscar is structured in the form of different classes interconnected with various attributes and their values at the input side, while as the output of the system the user can expect (re)design recommendations leading to achievement of certain design goals that can improve the ergonomic value of the product (hand tool) being developed.

An industrial example was used as a case study to test the correctness, reliability and usefulness of the knowledge base. A rear handle of the pneumatic hammer was redesigned for this purpose using recommendations derived by the system. The redesigned handle demonstrates significant ergonomics improvements.

Following these conclusions, it may be summarised that the intelligent decision support to the ergonomic design process represent added value to the existing ergonomic CAD tools that enable various ergonomic analyses, but fail to provide engineering advice on how to improve the ergonomic value of a design candidate that is the subject of ergonomic evaluation.

\section{REFERENCES}

[1] Fain, N., Moes, N., Duhovnik, J. (2010). The role of the user and the society in new product development. Strojniški vestnik - Journal of Mechanical Engineering, vol. 56, no. 7-8, p. 521-530.

[2] Kroemer, K., Kroemer, H., Kroemer-Elbert, K. (2001). Ergonomics - How to design for ease and efficiency. Prentice Hall, New York.

[3] Liu, Y. (2003). The aesthetic and the ethic dimensions of human factors and design. Ergonomics, vol. 46, no. 13/14, p. 1293-1305, DOI:10.1080/0014013031000161 0838 .

[4] Karkowski, W., Genaidy, A.M., Asfour, S.S. (1990). Computer-Aided Ergonomics. Taylor \& Francis, London.

[5] Porter, J.M., Freer, M.T., Case, K. (1999). Computer Aided Ergonomics. Engineering Designer, vol. 25, no. 2, p. 4-9.

[6] Feyen, R., Liu, Y., Chaffin, D., Jimmerson, G., Joseph, B. (2000). Computer-aided ergonomics: a case study of incorporating ergonomics analyses into workplace design. Applied Ergonomics, vol. 31, no. 3, p. 291-300, DOI:10.1016/S0003-6870(99)00053-8.

[7] Gill, S.A., Ruddle, R.A. (1998). Using virtual humans to solve real ergonomic design problems. Proceedings of IEEE International Conference on Simulation, Conference Publication no.457, p. 223-229.

[8] Launis, M., Lehtela, J. (1992). ErgoSHAPE: A design oriented ergonomic tool for AutoCAD. Mattila, M., Karkowski, W. (eds.), Computer Applications in 
Ergonomics, Occupational Safety, and Health, Elsevier, Amsterdam, p. 121-128.

[9] Davidoff, N.A., Freivalds, A. (1993). A graphic model of the human hand using CATIA. International Journal of Industrial Ergonomics, vol. 12, p. 255-264, DOI:10.1016/0169-8141(93)90095-U.

[10] Hammadi, M., Choley, J.Y., Penas, O., Louati, J., Rivière, A., Haddar, M. (2011). Layout optimization of power modules using a sequentially coupled approach. International Journal of Simulation Modelling, vol. 10, no. 3, p. 122-132, DOI:10.2507/IJSIMM10(3)2.183.

[11] Brunetti, G., Golob, B. (2000). A feature-based approach towards an integrated product model including conceptual design information. ComputerAided Design, vol. 32, p. 877-887, DOI:10.1016/ S0010-4485(00)00076-2.

[12] Kremljak, Z., Polajnar, A., Buchmeister, B. (2005). A heuristic model for the development of production capabilities. Strojniški vestnik - Journal of Mechanical Engineering, vol. 51, no. 11, p. 674-691.

[13] Nagamachi, M. (1995). Kansei engineering: a new ergonomic consumer oriented technology for product development. International Journal of Industrial Ergonomics, vol. 15, p. 13-24, DOI:10.1016/01698141(95)90025-X.

[14] Butters, L.M., Dixon, R.T. (1998). Ergonomics in consumer product evaluation: an evolving process. Applied Ergonomics, vol. 29, no. 1, p. 55-58, DOI:10.1016/S0003-6870(97)88805-9.

[15] Gielingh, W. (2008). Cognitive product development: A method for continuous improvement of products and processes. Strojniški vestnik - Journal of Mechanical Engineering, vol. 54, no. 6, p. 385-397.

[16] Du, S., Wu, Q., Wang, Y., Yi, Z. (2009). Study of Method for Computer Aided Ergonomics Knowledge Management and Design Aiming at Product Design. Computer-Aided Industrial Design \& Conceptual Design, p. 1176-1180.

[17] Liu, Y. (2003). Engineering aesthetics and aesthetic ergonomics: Theoretical foundations and a dual-process research methodology. Ergonomics, vol. 46, no. 13/14, p. 1273-1292, DOI:10.1080/00140130310001610829.

[18] Bratko, I. (2011). Prolog programming for artificial intelligence. Addison-Wesley, Harlow.

[19] Chein, M., Mugnier, M.L. (2009). Graph-based knowledge representation: Computational foundations of conceptual graphs. Springer, London.

[20] Awad, E. M. (2003). Building knowledge automation expert systems: With Exsys CORVID, EXSYS Inc, Albuquerque.

[21] Kuijt-Evers, L.F.M., Groenesteijn, L., De Looze, M.P., Vink, P. (2004). Identifying factors of comfort in using hand tools. Applied Ergonomics, vol. 35, 453-458, DOI:10.1016/j.apergo.2004.04.001.

[22] Cacha, C.A. (1999). Ergonomics and Safety in Hand Tool Design. Lewis Publishers, Boca Raton.

[23] Kong, Y., Lowe, B. D. (2005). Optimal cylindrical handle diameter for grip force tasks. International Journal of Industrial Ergonomics, vol. 35, no. 6, p. 495-507, DOI:10.1016/j.ergon.2004.11.003.

[24] Palčič, I., Buchmeister, B., Polajnar, A. (2010). Analysis of innovation concepts in Slovenian manufacturing companies. Strojniški vestnik - Journal of Mechanical Engineering, vol. 56, no. 12, p. 803-810.

[25] Fandiño Pita, J., Wang, Q. (2010). A simulation approach to facilitate manufacturing system design. International Journal of Simulation Modelling, vol. 9, no. 3, p. 152-164, DOI:10.2507/IJSIMM09(3)4.162.

[26] Hackenschmidt, R., Alber-Laukant, B., Rieg, F. (2011). Simulating nonlinear materials under centrifugal forces by using intelligent cross-linked simulations. Strojniški vestnik - Journal of Mechanical Engineering, vol. 57, no. 7-8, p. 531-538, DOI:10.5545/sv-jme.2011.013.

[27] Toma, M., Njilie, F. E. A., Ghajari, M., Galvanetto, U. (2010). Assessing motorcycle crash-related head injuries using finite element simulations. International Journal of Simulation Modelling, vol. 9, no. 3, p. 143151, DOI:10.2507/IJSIMM09(3)3.164. 